\title{
Mandibular Overdentures Supported by Two vs Four Endosteal Implants: A Retrospective Cohort Study
}

\author{
Hoseinali Mahgoli ${ }^{1}$, Sina Asadi ${ }^{2}$, Mohammadreza Hajmahmoudi $^{3}$, Mohammad Moharrami ${ }^{4}$, Mahnaz Arshad ${ }^{5}$
}

\begin{abstract}
Aim: Documentation of marginal bone resorption caused by implant-supported mandibular overdentures is scarce. This study sought to evaluate marginal bone resorption, survival rate, patient satisfaction, peri-implant soft tissue status, and prosthetic aftercare of mandibular overdentures supported by two vs four implants.

Materials and methods: This retrospective cohort study evaluated 92 edentulous patients presented to the Implant Center of Tehran University of Medical Sciences; out of which, 46 patients received overdentures supported by two Implantium implants (group A), while the remaining 46 received overdentures supported by four Implantium implants (group B). Standard radiographic indices were assessed following the delivery of overdenture and after 2 years of functional loading. Clinical evaluation was performed after 2 years of function. Data were analyzed using the $t$ test (for continuous variables) and the Mann-Whitney test (for ordinal variables).

Results: In group A, two implants were lost in one patient. The groups were not significantly different in terms of clinical or radiographic parameters $(p>0.05)$. Patient satisfaction and prosthetic aftercare were not significantly different in groups $A$ and $B(p>0.05)$.

Conclusions: During the 2-year evaluation period, the clinical and radiographic parameters were the same in patients who received overdentures supported by two or four implants.

Clinical significance: Successful results may be obtained by the use of mandibular overdentures supported by two or four implants.

Keywords: Endosseous dental implants, Mandibular overdenture, Marginal bone loss, Peri-implant parameters.

The Journal of Contemporary Dental Practice (2019): 10.5005/jp-journals-10024-2562
\end{abstract}

\section{INTRODUCTION}

Edentulous patients with severely resorbed mandibular alveolar ridge are not often satisfied with their conventional denture due to its mobility. ${ }^{1,2}$ Such patients mainly complain of their decreased chewing ability and insufficient retention or stability of denture. ${ }^{3}$ To overcome this problem, endosseous implants can be placed in the mandible to provide support for the overdenture. ${ }^{4}$ This treatment modality significantly enhances patient satisfaction since it improves mastication and chewing efficiency. Two or more implants can be placed in the mandible to support an overdenture. Evidence shows that two implants are adequate to ensure clinical success of treatment. ${ }^{5}$ A treatment concept utilizing a two- or four-implant-supported mandibular overdenture is generally recommended. ${ }^{2,6}$ Controversy exists regarding the adequate number of implants to support an overdenture; the most commonly adopted choice is either a two- or four-implantsupported overdenture. ${ }^{7}$ More studies are required to assess and compare the efficacy of two- and four-implant-supported overdentures. ${ }^{8,9}$

No previous study has reported the clinical and radiographic outcomes of the placement of two or more implants to support mandibular overdentures. Therefore, this study aimed to evaluate marginal bone loss, survival rate, peri-implant hard and soft tissue status, prosthetic aftercare, and level of satisfaction of patients who received two- and four-implant-supported mandibular overdentures during a 2-year period.

\section{Materials and Methods}

This retrospective cohort study followed the principles of the Declaration of Helsinki. Also, this study was reviewed and approved
1,3,5 Dental Research Center, Dentistry Research Institute, Tehran University of Medical Sciences, Tehran, Iran; Department of Prosthodontics, International Campus, School of Dentistry, Tehran University of Medical Sciences, Tehran, Iran

${ }^{2,4}$ Dental Research Center, School of Dentistry, Tehran University of Medical Sciences, Tehran, Iran

Corresponding Author: Mahnaz Arshad, Department of Prosthodontic, School of Dentistry, International Campus, Tehran University of Medical Sciences, Khani Abad, Tehran, Iran, Phone: +98 2122273471, e-mail: ahnazarshad@yahoo.com

How to cite this article: Mahgoli $\mathrm{H}$, Asadi $\mathrm{S}$, et al. Mandibular Overdentures Supported by Two vs Four Endosteal Implants: A Retrospective Cohort Study. J Contemp Dent Pract 2019;20(5):582-586.

Source of support: Nil

Conflict of interest: None

by the Ethical Board at the Prosthodontic Department of Tehran University of Medical Sciences. The committee of medical ethics of this university approved all the procedures and materials as well. All patients were briefed about the study and signed informed consent forms. The minimum sample size was calculated to be 41 patients according to a study by Visser et al., ${ }^{4}$ assuming the mean standard deviation of $0.8 \mathrm{~mm}$ for pocket depth using the Minitab software. Finally, 46 patients were enrolled considering the possibility of $10 \%$ dropouts.

\section{Patient Selection}

We assessed 92 patients ( 40 females and 52 males) with a mean age of 52.3 years (range $40-70$ years) selected from the Implant Center of Dental Faculty of Tehran University of Medical Sciences.

(0) The Author(s). 2019 Open Access This article is distributed under the terms of the Creative Commons Attribution 4.0 International License (https://creativecommons. org/licenses/by-nc/4.0/), which permits unrestricted use, distribution, and non-commercial reproduction in any medium, provided you give appropriate credit to the original author(s) and the source, provide a link to the Creative Commons license, and indicate if changes were made. The Creative Commons Public Domain Dedication waiver (http://creativecommons.org/publicdomain/zero/1.0/) applies to the data made available in this article, unless otherwise stated. 
They all received a maxillary complete denture and a two- or fourimplant-supported mandibular overdenture (Dentium, Seoul, Korea). The retention mechanism of the overdenture was ball attachment in two-implant-supported overdentures and ball and bar in four-implant-supported overdentures; 46 patients received two Implantium implants (group A), while the remaining 46 received four Implantium implants (group B).

The inclusion criteria were good oral hygiene and absence of systemic conditions affecting bone metabolism or oral mucosa, such as diabetes mellitus, renal disease, and osteoporosis.

The exclusion criteria were a previous history of radiotherapy in the head and neck region, heavy smoking (> 20 cigarettes/day), severe parafunctional habits causing prosthetic tooth wear or denture fracture, history of implant failure, and life-threatening diseases (American Society of Anesthesiologists (ASA) classifications III and IV). ${ }^{10}$ The patients were provided with necessary information about the study. Written informed consent was obtained from all participants in full accordance with the ethical principles by someone who did not participate in the study design. The patients were subjected to clinical and radiographic examinations and filled out the satisfaction questionnaire.

\section{Clinical Analysis}

All measurements were performed by an independent observer. The lost implants and those with mobility were scored. The presence of plaque (Table 1) and calculus (Table 2) and the bleeding score (Table 3) were evaluated as described by Mombelli et al. ${ }^{11}$ The modified Loe and Silness index was used to assess peri-implant inflammation (Table 4). ${ }^{12}$ Probing depth was determined at four sites around each implant (mesial, distal, labial, and lingual). A periodontal probe was used for this purpose. The pocket probing depth was measured as the distance between the gingival margin and the periodontal probe tip. The percussion test was also carried out (Table 5). Periotest (Periotest M, Medizintechnik Gulden,

Table 1: Modified plaque index scores

\begin{tabular}{|c|c|}
\hline Score 0 & No plaque \\
\hline Score 1 & $\begin{array}{l}\text { Plaque detectable by running a probe across the } \\
\text { smooth marginal surface of the abutment }\end{array}$ \\
\hline Score 2 & Plaque visible by the naked eye \\
\hline Score 3 & Abundance of plaque \\
\hline
\end{tabular}

Table 2: Calculus index as described by Mombelli et al. ${ }^{11}$

\begin{tabular}{ll}
\hline Score 0 & Presence of calculus \\
Score 1 & Absence of calculus \\
\hline
\end{tabular}

Table 3: Bleeding index as described by Mombelli et al. ${ }^{11}$

\begin{tabular}{ll}
\hline Score 0 & No bleeding on probing \\
Score 1 & Isolated bleeding spots \\
Score 2 & A confluent red line of blood along the mucosal margin \\
Score 3 & Heavy or profuse bleeding \\
\hline
\end{tabular}

Table 4: Peri-implant inflammation index

\begin{tabular}{|c|c|}
\hline Score 0 & Normal peri-implant mucosa \\
\hline Score 1 & $\begin{array}{l}\text { Mild inflammation, slight change in color, and slight } \\
\text { edema }\end{array}$ \\
\hline Score 2 & Moderate inflammation, redness, edema, and glazing \\
\hline Score 3 & $\begin{array}{l}\text { Severe inflammation, marked redness and edema, } \\
\text { and ulceration }\end{array}$ \\
\hline
\end{tabular}

Table 5: Percussion test score

\begin{tabular}{ll}
\hline Score 0 & High percussion sound \\
Score 1 & Dull percussion sound \\
\hline
\end{tabular}

Germany) was used to assess implant mobility. In order to determine any sensory disturbances, the patient's lip and chin regions were touched with a cotton pellet.

\section{Radiographic Assessment}

Digital periapical radiographs were obtained with the parallel technique, such that the length of the implants on consecutive radiographs would be relatively constant. ${ }^{13,14}$ Radiographs were examined by one calibrated examiner. Prior to radiography, the system was calibrated using the implant diameter to account for image distortion. The linear distance between the proximal crestal bone level and the implant shoulder was measured at the mesial and distal aspects of the implant. Measurements were performed using image measurement software (Planmeca Romexis Viewer, Planmeca USA). The actual implant length was used to remove magnification of all radiographs. To detect marginal peri-implant bone loss, the last radiograph (T2: obtained 2 years after overdenture delivery) was compared with the previous one ( $\mathrm{T} 1$ : obtained after prosthodontic treatment) by two experienced examiners.

\section{Patient Satisfaction}

A questionnaire focusing on patient complaints was used, which consisted of 51 items regarding the functional problems of the lower and upper dentures, speech, retention, mastication, facial aesthetics, and denture aesthetics. The severity of each complaint was reported using a four-point scale $(0=$ no complaint, $1=$ slight, $2=$ moderate, and $3=$ severe complaint). ${ }^{15}$

\section{Data Collection}

At T1 and T2, the patients underwent clinical examination and filled out the patient satisfaction questionnaire. Also, the patients were requested to continuously score the prosthetic and surgical aftercare during the 2-year functional period.

\section{Statistical Analysis}

Data were analyzed using the $t$ test (for continuous variables) and the Mann-Whitney test (for ordinal variables). Pearson's correlation test was used to assess the correlation between variables via Statistical Package for the Social Sciences (SPSS) version 22.0 (SPSS Inc., IL, USA). A $p$ value of $<0.05$ was considered to be statistically significant.

\section{Results}

At T2, two patients in group A and one patient in group B were lost to follow-up. No significant differences were observed between the two groups.

\section{Clinical Parameters}

One patient in group A lost two implants during the 2-year functional period (99.2\% survival rate at 2 years following loading).

\section{Periodontal Parameters}

The two- and four-implant groups were not significantly different in terms of pocket probing depth, plaque index, calculus score, gingival score, or bleeding score. Table 6 lists the mean scores of peri-implant parameters. Suppuration upon probing was not seen in any of the patients. 
Table 6: Mean values of plaque index (0-3), calculus index (0-1), gingival index (0-3), bleeding index (0-3), and probing depth in millimeters at T2

\begin{tabular}{lll}
\hline & Group A & Group B \\
\hline Mean plaque index & 0.9 & 1.1 \\
Mean calculus index & 0.4 & 0.6 \\
Mean bleeding index & 0.2 & 0.3 \\
Mean probing depth in mm & 2.4 & 2.7 \\
Mean gingival index & 0.4 & 0.4 \\
\hline
\end{tabular}

\section{Percussion and Mobility}

No significant mobility was observed between the two groups. The percussion test did not reveal a dull sound in any of the patients. Marginal bone loss had no correlation with Periotest values.

\section{Sensory Disturbances of the Lip and Chin Region}

None of the patients had sensory disturbances of the lip and chin region.

\section{Patient Satisfaction}

Table 7 shows the mean scores acquired by patients in the patient satisfaction questionnaire. The two groups were the same with regard to patient satisfaction.

\section{Radiographic Parameters}

A total of 176 radiographs of 88 patients were evaluated. Marginal bone loss was nonsignificantly greater in group A. Radiographic findings had no correlation with other periodontal parameters.

The average bone loss was $0.3 \mathrm{~mm}$ in group $A$ and $0.2 \mathrm{~mm}$ in group $B$ during the 2-year period. The two groups were the same in terms of bone loss.

\section{Postoperative Care}

Prosthetic aftercare mainly consisted of placing new clips and denture base repair. No surgical interventions were required in the groups. The overall prosthetic aftercare is listed in Table 8.

Table 7: Mean scores for denture complaints (0-3)

\begin{tabular}{lll}
\hline & Group A & Group B \\
\hline Functional complaints mandibular denture & 0.5 & 0.4 \\
Functional complaints maxillary denture & 0.5 & 0.3 \\
Functional complaints in general & 0.7 & 0.4 \\
Facial aesthetics & 0.5 & 0.4 \\
Aesthetics of denture & 0.3 & 0.5 \\
Retention & 0.2 & 0.1 \\
Speech & 0.2 & 0.2 \\
Mastication & 0.7 & 0.4 \\
\hline
\end{tabular}

Table 8: Prosthetic and surgical aftercare during 2 years of follow-up

\begin{tabular}{lll}
\hline & Group A & Group B \\
\hline New clips & 12 & 15 \\
Relining upper denture & 4 & 2 \\
Relining lower denture & 0 & 1 \\
Readjustment of occlusion & 2 & 1 \\
New upper denture & 0 & 0 \\
New lower denture & 0 & 0 \\
Palatal mucosal grafts & 0 & 0 \\
Gingivectomy & 0 & 0 \\
\hline
\end{tabular}

\section{Discussion}

This study examined the treatment outcome in patients who received mandibular implant-supported overdentures. The survival rate, complications, aftercare, peri-implant parameters, and patient satisfaction were all evaluated.

In this study, a 2-year survival rate of more than $99 \%$ was observed for Implantium (Dentium, Seoul, Korea) implants, which is comparable to the rates reported by some other studies ranging from $86 \%$ to $99 \% .{ }^{4,16-21}$ Meijer et al., compared two- and four-implant-supported overdentures and found no significant difference. ${ }^{24}$ Visser et al., reported $100 \%$ and $98 \%$ survival rates for four-implant- and two-implant-supported overdentures, respectively. ${ }^{4}$ The survival rate reported by Wismeijer et al., was $97 \% .^{22}$ This rate was $99 \%$ in a study by Batenburg et al. ${ }^{6}$ Fixture loss in mandibular overdentures had a frequency of $6 \%$ in a study by Engquist et al. ${ }^{23}$ This may be explained by the patient selection. Engquist et al., used overdentures for patients with severely resorbed jawbone not allowing placement of an adequate number of fixtures for a bridge (56\%). In this study, patients with extremely resorbed jawbone comprised only $2 \%$ of the study group. Additionally, it should be noted that a study conducted in Sweden reported $1 \%$ failure rate after loading.

The necessity to reattach the loose clips or replace them was the most frequent complication of implant-supported overdentures in our study. This study showed a similar rate of prosthetic complications in two- and four-implant groups, which is different from the findings of Visser et al., ${ }^{4}$ who reported a higher need for prosthetic aftercare in patients with two-implant overdentures compared to those with four-implant overdentures. However, Meijer et al., ${ }^{24}$ and Stoker et al., ${ }^{25}$ found no significant difference in prosthetic maintenance of two- and four-implant groups.

In our study, the two groups were the same in terms of patient satisfaction. This is in agreement with the results of other studies comparing two- and four-implant-supported overdentures with regard to patient satisfaction. ${ }^{4,24,26,27}$

The mean calculus score, plaque index, gingival index, and bleeding score were very low in both groups in our study, which is in line with the results of Visser et al., ${ }^{4}$ and Meijer et al., ${ }^{19,20}$ who used the same criteria as ours. In our study, however, radiographically visible peri-implant marginal bone loss, pocket depth, and clinically observed inflammation were not correlated. According to Batenburg et al., ${ }^{28}$ this may be partly due to the fact that some patients experience severe pain when measuring their pocket depth. Therefore, the possibility of objective measurement of real pocket probing depth around dental implants is questionable. This is not in line with the results of Stroker et al., ${ }^{29}$ who reported significantly higher plaque index in the four-implant group in comparison to the two-implant group. According to Stroker et al., ${ }^{29}$ the plaque index is influenced by the smaller distance between implants making it more difficult to clean the bars. The loading and type of superstructure may influence the marginal bone loss; with more implants, the risk of peri-implantitis increases. Concerning the lack of a correlation between the presence of plaque and bone loss, observations of this study seem to be in contrast to those of Lindquist et al., ${ }^{30}$ who observed $50 \%$ more bone loss around implants with plaque-carrying abutments over a 6-year period. Further investigations are required on the prevalence of periimplantitis in patients with mandibular overdentures.

Marginal bone loss is a critical criterion for a successful implant which usually occurs in the first year rather than the subsequent 
years. ${ }^{27,31,32}$ The acceptable rate of vertical bone loss is $<0.2 \mathrm{~mm}$ annually after the first year of implant placement. ${ }^{33}$

In the present study, patients with two- and four-implantsupported mandibular overdentures had no significant difference in terms of marginal bone loss, which supports the findings of previous studies. ${ }^{4,6,26,34}$ Stoker et al., ${ }^{29}$ however, evaluated 100 patients with three types of mandibular implant-supported overdentures in an 8-year randomized clinical trial. They evaluated aftercare and performed cost analysis. They showed a lower rate of marginal bone loss in those with two compared to four implants and stated that two implants may be preferred for implant-supported overdentures of the mandible. Many studies have evaluated marginal bone loss in patients with implant-supported overdentures of the mandible. As a result of variations in clinical and radiographic parameters used, comparison of such studies would not yield accurate results. Four studies have reported optimal survival rates for four-implantsupported overdentures. ${ }^{35-38}$ The long-term follow-up results in two other studies may explain the high success rates. ${ }^{39,40}$ Superior stability may be achieved by the placement of four implants. Moreover, the movements of the overdenture would be minimized and excessive loading, which compromises osseointegration, would be prevented. ${ }^{40}$

The main limitation of our study was the short follow-up, which was due to the interim nature of this study. A long-term study with over 10 years of follow-up is recommended to compare overdentures supported by different numbers of implants with different types of attachments.

\section{Conclusion}

Two endosteal implants supporting mandibular overdenture with ball attachments seem adequate. The number of implants did not significantly influence denture maintenance, patient satisfaction, or peri-implant parameters. However, long-term studies are warranted on marginal bone loss.

\section{Clinical Significance}

According to the results of this study, mandibular overdenture with two implants is an appropriate treatment in patients with financial problems or severe resorption of the posterior mandible.

\section{References}

1. Shirani G, Arshad M, et al. Immediate reconstruction of a large mandibular defect of locally invasive benign lesions (a new method). J Craniofac Surg 2007;18(6):1422-1428. DOI: 10.1097/ scs.0b013e3180a77352.

2. Batenburg RH, Meijer HJ, et al. Treatment concept for mandibular overdentures supported by endosseous implants: a literature review. Int J Oral Maxillofac Implants 1998;13(4):539-545.

3. Van Waas MA. The influence of clinical variables on patients' satisfaction with complete dentures. J Prosthet Dent 1990;63(3):307-310.

4. Visser A, Raghoebar GM, et al. Mandibular overdentures supported by two or four endosseous implants. Clin Oral Implants Res 2005;16(1):19-25.

5. Tavakolizadeh S, Vafaee F, et al. Comparison of marginal bone loss and patient satisfaction in single and double-implant assisted mandibular overdenture by immediate loading. J Adv Prosthodont 2015;7(3):191-198. DOI: 10.4047/jap.2015.7.3.191.

6. Batenburg RH, Raghoebar GM, et al. Mandibular overdentures supported by two or four endosteal implants: a prospective, comparative study. Int J Oral Maxillofac Surg 1998;27(6):435-439.
7. Zarb G, Schmitt A. The longitudinal clinical effectiveness of osseointegrated dental implants: the Toronto Study. Part II: the prosthetic results. J Prosthet Dent 1990;64(1):53-61.

8. Antczak-Bouckoms A, Chalmers T. The importance of design and analysis in clinical trials. J Oral Implantol 1987;14(1):36-42.

9. Barmes $D$. The state of the science of patient outcome research. J Oral Implantol 1990;16(4):245.

10. Daabiss M. American Society of Anaesthesiologists physical status classification. Indian J Anaesth 2011;55(2):111. DOI: 10.4103/00195049.79879.

11. Mombelli A, Oosten $M$, et al. The microbiota associated with successful or failing osseointegrated titanium implants. Oral Microbiol Immunol 1987;2(4):145-151.

12. Silness J, Loe H. Periodontal disease in pregnancy II. Correlation between oral hygiene and periodontal condition. Acta Odontol Scand 1964;22(1):121-135.

13. Stramotas S, Geenty JP, et al. The reliability of crown-root ratio, linear and angular measurements on panoramic radiographs. Clin Orthod Res 2000;3(4):182-191.

14. Zhang L, Geraets $W$, et al. A new classification of peri-implant bone morphology: a radiographic study of patients with lower implant-supported mandibular overdentures. Clin Oral Implants Res 2014;25(8):905-909. DOI: 10.1111/clr.12193.

15. Vervoorn JM, Duinkerke AS, et al. Assessment of denture satisfaction. Community Dent Oral Epidemiol 1988;16(6):364-367.

16. Mericske-Stern R. Overdentures with roots or implants for elderly patients: a comparison. J Prosthet Dent 1994;72(5):543-550.

17. Jemt $\mathrm{T}$, Chai J, et al. A 5 -year prospective multicenter follow-up report on overdentures supported by osseointegrated implants. Int J Oral Maxillofac Implants 1996;11(3):291-298.

18. Naert I, Gizani S, et al. A 5-year randomized clinical trial on the influence of splinted and unsplinted oral implants in the mandibular overdenture therapy. Part I: peri-implant outcome. Clin Oral Implants Res 1998;9(3):170-177.

19. Meijer HJ, Geertman ME, et al. Implant-retained mandibular overdentures: 6-year results of a multicenter clinical trial on 3 different implant systems. Int J Oral Maxillofac Surg 2001;59(11):1260-1268. DOI: 10.1053/joms.2001.27512.

20. Meijer HJ, Raghoebar GM, et al. A controlled clinical trial of implantretained mandibular overdentures; five-years' results of clinical aspects and aftercare of IMZ implants and Brånemark implants. Clin Oral Implants Res 2000;11(5):441-447.

21. Behneke A, Behneke N, et al. A 5-year longitudinal study of the clinical effectiveness of ITI solid-screw implants in the treatment of mandibular edentulism. Int J Oral Maxillofac Implants 2002;17(6):799-810.

22. Wismeijer $D$, Van Waas MA, et al. Clinical and radiological results of patients treated with three treatment modalities for overdentures on implants of the ITI ${ }^{\oplus}$ Dental Implant System. A randomized controlled clinical trial. Clin Oral Implants Res 1999;10(4):297-306.

23. Engquist $B$, Bergendal $T$, et al. A retrospective multicenter evaluation of osseointegrated implants supporting overdentures. Int J Oral Maxillofac Implants 1988;3(2):129-134.

24. Meijer HJ, Raghoebar GM, et al. Mandibular overdentures supported by two or four endosseous implants: a 10-year clinical trial. Clin Oral Implants Res 2009;20(7):722-728. DOI: 10.1111/j.16000501.2009.01710.x.

25. Stoker G, Wismeijer D, et al. An eight-year follow-up to a randomized clinical trial of aftercare and cost-analysis with three types of mandibular implant-retained overdentures. J Dent Res 2007;86(3):276-280. DOI: 10.1177/154405910708600315.

26. Wismeijer Dv, Van Waas $M$, et al. Patients' perception of sensory disturbances of the mental nerve before and after implant surgery: a prospective study of 110 patients. Br J Oral Maxillofac Surg 1997;35(4):254-259.

27. Timmerman R, Stoker G, et al. An eight-year follow-up to a randomized clinical trial of participant satisfaction with three types of mandibular 
implant-retained overdentures. J Dent Res 2004;83(8):630-633. DOI: $10.1177 / 154405910408300809$.

28. Batenburg $R$, van Oort $R$, et al. Overdentures supported by two IMZ implants in the lower jaw. A retrospective study of peri-implant tissues. Implant Dent 1995;4(3):203.

29. Stoker G, van Waas R, et al. Long-term outcomes of three types of implant-supported mandibular overdentures in smokers. Clin Oral Implants Res 2012;23(8):925-929. DOI: 10.1111/j.16000501.2011.02237.x.

30. Lindquist LW, Rockler $B$, et al. Bone resorption around fixtures in edentulous patients treated with mandibular fixed tissue-integrated prostheses. J Prosthet Dent 1988;59(1):59-63.

31. Albrektsson T, Zarb G, et al. The long-term efficacy of currently used dental implants: a review and proposed criteria of success. Int J Oral Maxillofac Implants 1986;1(1):11-25.

32. Oh T-J, Yoon J, et al. The causes of early implant bone loss: myth or science? J Periodontol 2002;73(3):322-333. DOI: 10.1902/ jop.2002.73.3.322.

33. Albrektsson $\mathrm{T}$, Dahl E, et al. Osseointegrated oral implants: a Swedish multicenter study of 8139 consecutively inserted Nobelpharma implants. J Periodontol 1988;59(5):287-296. DOI: 10.1902/jop.1988.59.5.287.

34. Wismeijer $D$, Van Waas $M$, et al. Patient satisfaction with implantsupported mandibular overdentures: a comparison of three treatment strategies with ITI-dental implants. Int J Oral Maxillofac Surg 1997;26(4):263-267.

35. Donatsky O. Osseointegrated dental implants with ball attachments supporting overdentures in patients with mandibular alveolar ridge atrophy. Int J Oral Maxillofac Implants 1993;8(2):162-166.

36. Makkonen TA, Holmberg S, et al. A 5-year prospective clinical study of Astra Tech dental implants supporting fixed bridges or overdentures in the edentulous mandible. Clin Oral Implants Res 1997;8(6): 469-475.

37. Romeo E, Chiapasco M, et al. Implant-retained mandibular overdentures with ITI implants: a comparison of 2-year results between delayed and immediate loading. Clin Oral Implants Res 2002;13(5):495-501.

38. Heschl A, Payer M, et al. Overdentures in the edentulous mandible supported by implants and retained by a Dolder bar: a 5-year prospective study. Clin Implant Dent Relat Res 2013;15(4):589-599. DOI: 10.1111/j.1708-8208.2011.00380.x.

39. Ferrigno N, Laureti $M$, et al. A long-term follow-up study of nonsubmerged ITI implants in the treatment of totally edentulous jaws: Part 1: ten-year life table analysis of a prospective multicenter study with 1286 implants. Clin Oral Implants Res 2002;13(3):260-273.

40. Chiapasco M, Gatti C, et al. Implant-retained mandibular overdentures with immediate loading: a retrospective multicenter study on 226 consecutive cases. Clin Oral Implants Res 1997;8(1):48-57. 